\title{
OPTIMIZATION OF HIGH QUALITY PRODUCTION IN HOT ROLLING MILLS USING ADVANCED PROCESS MODELS*
}

Detlef Ehlert ${ }^{1}$

Olaf Jepsen ${ }^{2}$

Gregor Schneider ${ }^{3}$

\begin{abstract}
Flexibility in terms of producing high sophisticated products with an exceptional wide range of properties and dimensions requires physical based process models for the generation of optimal set points. Therefore SMS applies since many years an integrated PSC ${ }^{\circledR}$ (pass schedule model), PCFC ${ }^{\circledR}$ (profile, contour and flatness model) and CSC (cooling section control) for the use in hot strip mills, CSP ${ }^{\circledR}$ plants and plate mills offering best possible product tolerances. Focus during the development of the model was made on the best possible physical description of the rolling process to minimize the need of complex adaptation algorithms. As an addition SMS has also developed a microstructure model to ensure the quality control with respect to mechanical properties and to save up the needs of taking samples. Beside of this the modular design of the Microstructure and Material Property Model (MPM) offers additional benefits to improve the accuracy of the other models, e. g. the recrystallization model in the finishing mill. Using the results of that model strain hardening or softening effects during rolling can be predicted and an optimum pass schedule can be calculated to avoid rolling stability problems related to phase transformation.
\end{abstract}

Keywords: Microstructure; Material property; Rolling stability; Physical process models.

1 Dipl.-Ing, Executive Vice President, Electrical and Automations Systems, SMS Group, Hilchenbach, NRW, Germany.

2 Dr.-Ing., General Manager Research and Development Basic Design Development Flat Rolling, SMS Group, Hilchenbach, NRW, Germany.

3 Dipl.-Ing, General Manager, Electrical and Automation Systems Level 2/Level 3 Automation, SMS Group, Hilchenbach, NRW, Germany. 


\section{AUTOMATION STRUCTURE}

High quality of expanding production is a top priority feature for a reproducible and stable rolling process. Consequently, an optimized treatment which follows production demands is needed for each individual product. Two main tasks arise from the described requirement:

- Establish a process route which follows defined rolling strategies and which takes limitations into account. Result of this task is the setup for the subordinate control system and belongs to the Level 2 (L2) within the automation architecture.

- A control system is needed to apply the setup to the rolling mill. The production progress is controlled by the Level 1 (L1) within the automation architecture. Additionally, the fast control system reacts to the usual scatter in process.
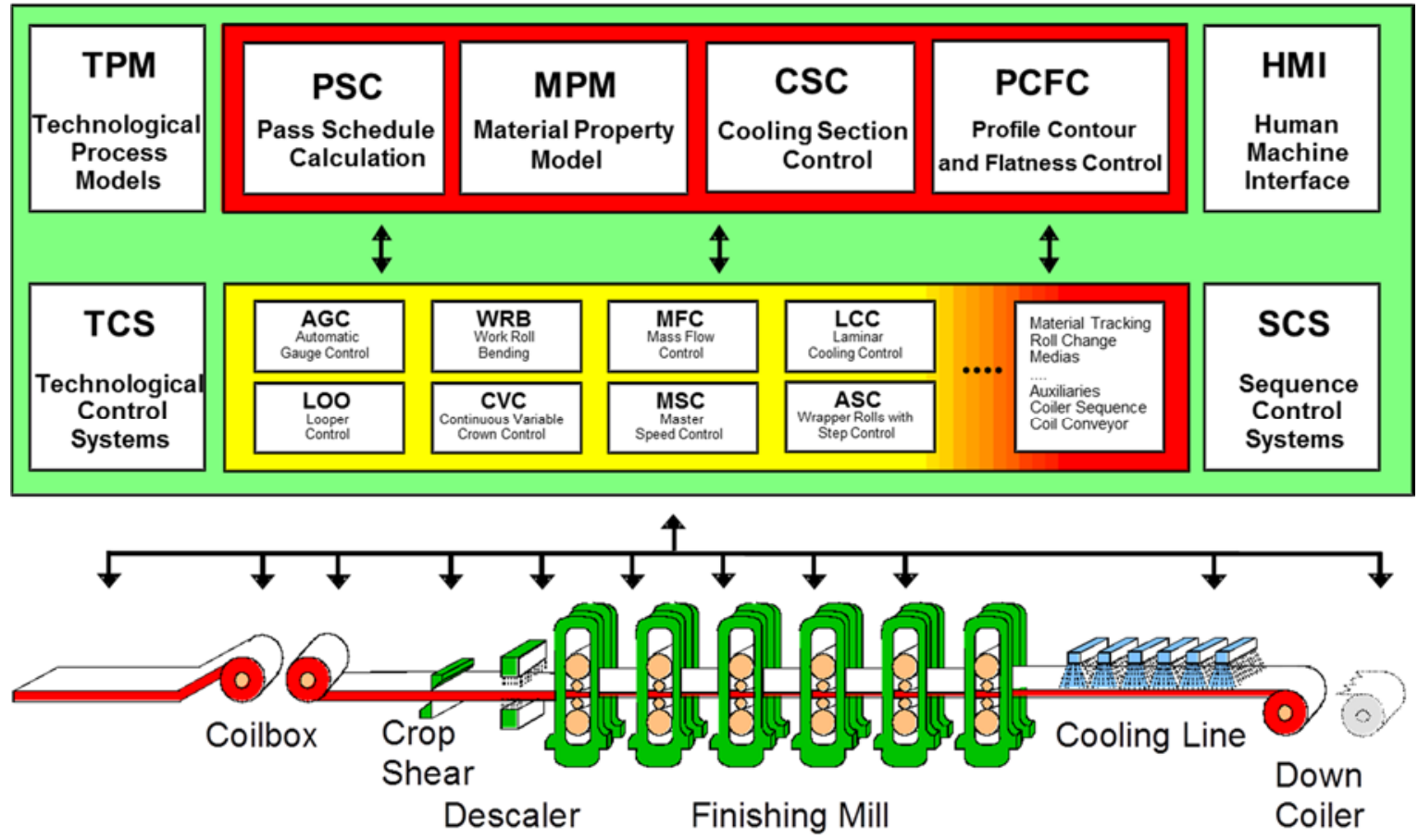

Figure 1: Schematic layout of the automation system of the hot strip mill.

One of the success factors of the SMS Siemag process automation is the usage of exactly the same models and algorithms as well for plant layout and design as for the use in the online environment. This provides matched solutions between mechanical design and automation, implementing the same technological ideas and enables the customer to exploit the full potential of technology and results in first class hot rolled products. Beside that it offers the whole range of back office support during commissioning and after sales service 
Model Shell for Application
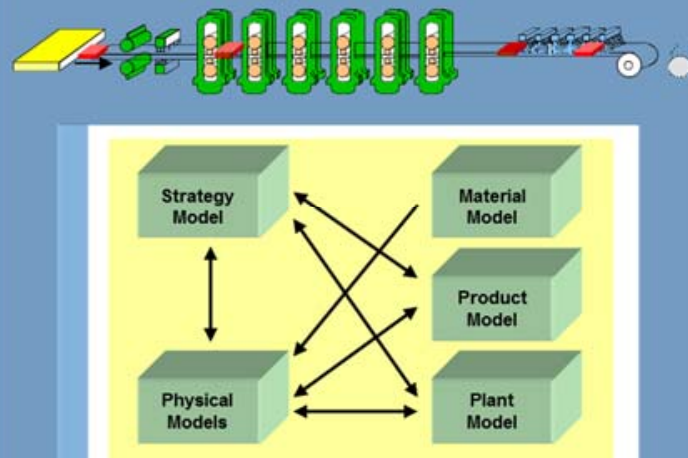

Model Kernel

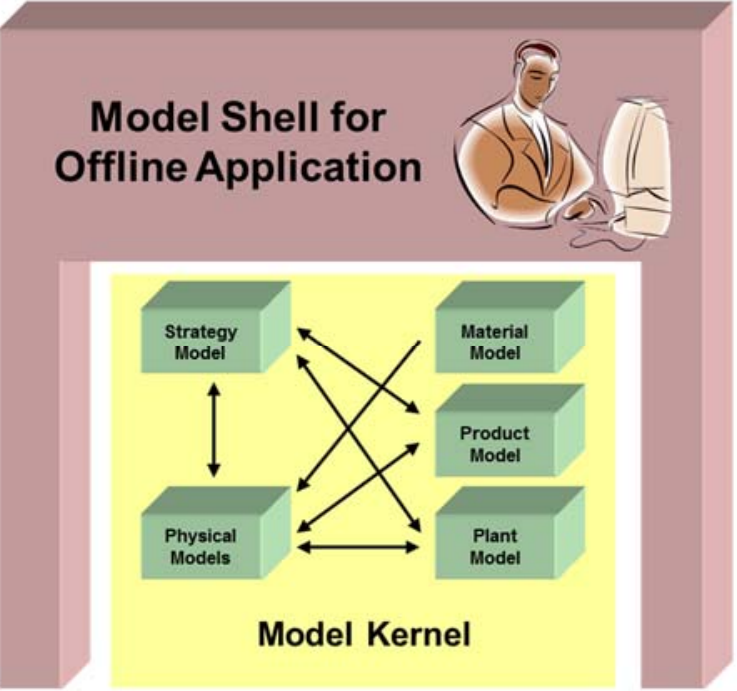

Figure 2: Structure of offline and online model

\section{MODELS IN A HOT STRIP MILL (HSM)}

The Level 2 process automation contains the following process models

- $\mathrm{PSC}^{\circledR}$

Pass schedule calculation

- $\mathrm{PCFC}^{\circledR}$

Profile Contour and Flatness Control including the RSM (roll state model)

- CSC Cooling Section Control

- MPM Microstructure and Material Property model

\subsection{PSC ${ }^{\circledR}$ Pass Schedule Calculation}

The Pass Schedule Calculation (PSC ${ }^{\circledR}$ ) ensures a high accuracy in the prediction of the process parameters due to extensive physical modeling of the rolling process combined with adaptation to actual measured values. Multiple calculation points over the product length, e.g. head, body and tail, are performed to ensure that the entire length of the product can be rolled without any limitations and that all necessary parameters and sensitivities are available for the inbar control functions located in the Level 1 automation.

In particular two sub models of the PSC ${ }^{\circledR}$ have to be highlighted:

- Material model

- Recrystallization model 


\subsubsection{Material model}

The material model describes the flow stress behavior of the various grades based on a "material data base". Grades are classified into material groups based on the chemical analysis. Each group contains a parameter set, respectively. The parameter set is used within a flow stress formula depending on temperature, plastic strain and plastic strain rate. The result of this calculation is used to calculate the roll force and torque. Beside the parameters of the calculation of the flow stress the material database also provides all necessary thermo physical constants like specific heat, heat expansion coefficients, etc. The material model can be easily extended by the customer with the help of special software tools provided by SMS Siemag.

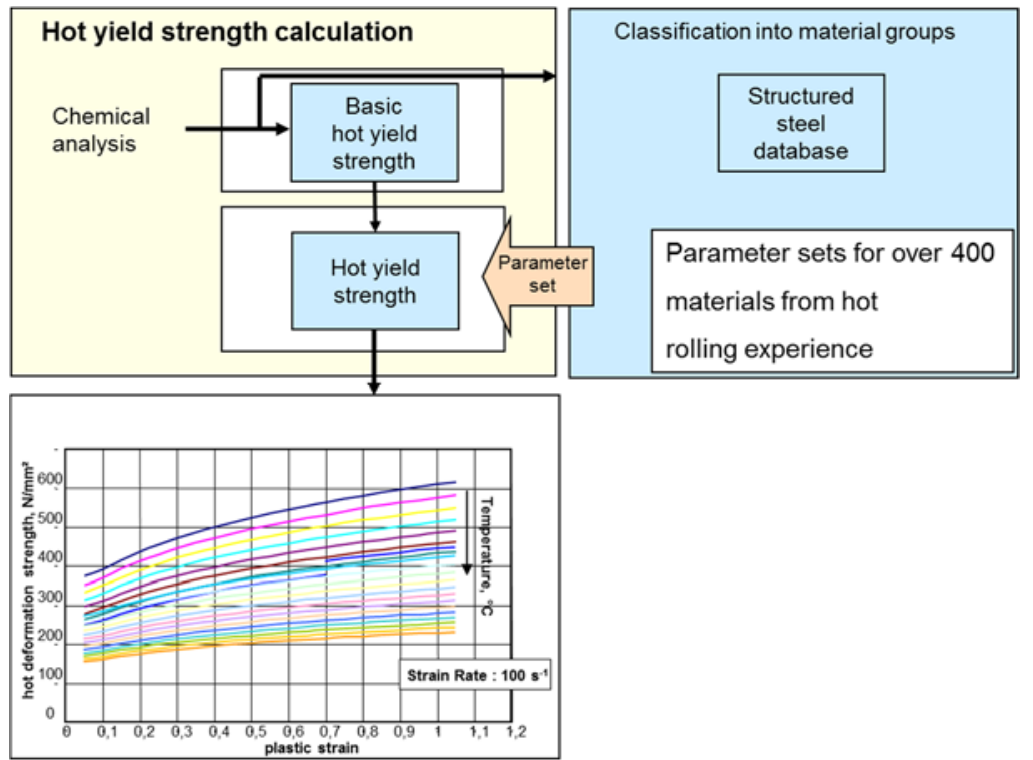

Figure 3: Concept of material model

\subsubsection{Recrystallization model}

The recrystallization model is a physical model which determines the reactions and the behavior of solid particles during hot rolling by means of adequate mathematical equations. This model considers static recrystallization (SRX), dynamic recrystallization (DRX) and grain growth.

Calculation starts with an initial austenite grain size before finishing mill. Grain growth to first stand will be calculated and then metallurgical phenomena of static or dynamic recrystallization will be simulated as a function of deformation conditions in the stands.

Dynamic recrystallization (DRX) occurs directly in the roll gap if the critical strain is less than the present strain. The time of meta-dynamic recrystallization is very short and grain growth starts immediately. If present strain is less than critical strain static recrystallization occurs. That means that a certain time is necessary for start of recrystallization. In case of static recrystallization (SRX) and short interval time between two stands a certain amount of rest deformation (accumulated strain) can reach next stand in case of incomplete static recrystallization. 


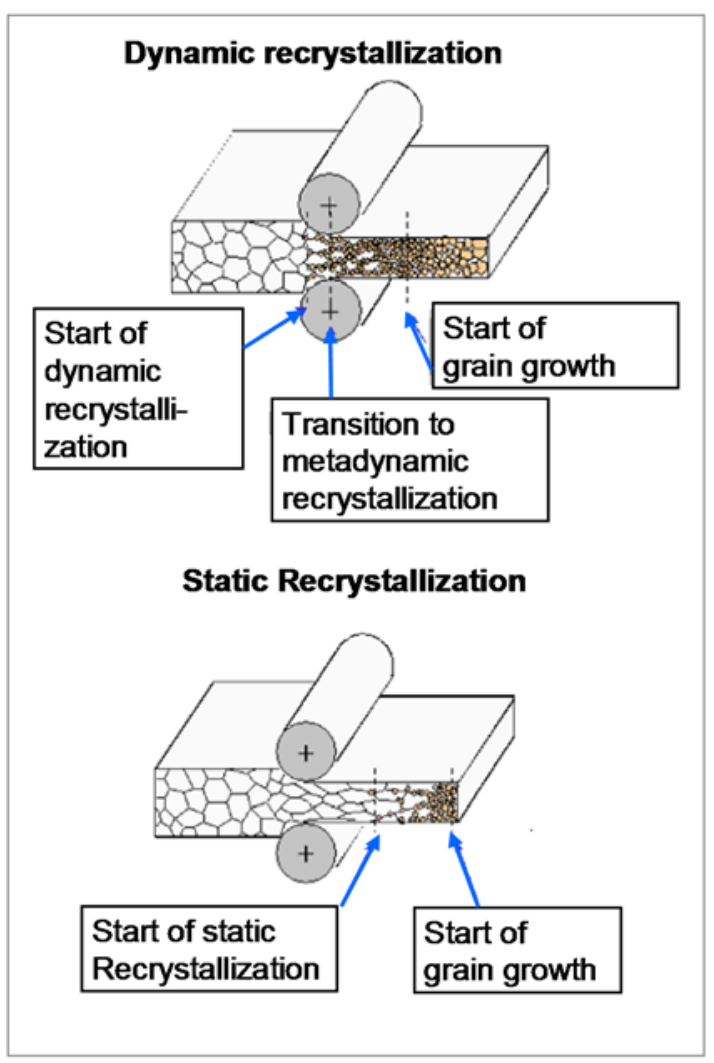

Figure 4: Static and dynamic recrystallization

Especially when rolling micro alloyed steel grades rolling stability can be critical due to hardening and softening of the material dependent on the temperature distribution over the width and the length. Knowing the recrystallization behavior the pass schedule can be optimized for the rolling of those critical steel grades to ensure stable rolling conditions over the entire length of the product.

\subsection{Profile, Contour and Flatness Control (PCFC $\left.{ }^{\circledR}\right)$}

The success story of the PCFC ${ }^{\circledR}$ started more than 25 years ago and in the meantime more than 100 installations are executed worldwide. In combination with the powerful setting systems $\mathrm{CVC}^{\circledR}$ plus and work roll bending the $\mathrm{PCFC}^{\circledR}$ provides best possible profile and flatness results in combination with minimized profile anomalies.

The following key functions have been added to the $\mathrm{PCFC}^{\circledR}$ in the recent years

- Cyclical shifting of $C V C^{\circledR}$ plus rolls for best possible rolling flexibility

- Contour control to minimize contour defects (edge built up, edge drop) and flatness defects of higher order (high frequency edge waves)

- Close interaction between $\mathrm{PSC}^{\circledR}$ and $\mathrm{PCFC}^{\circledR}$ providing extended setting capabilities for profile, contour and flatness by the use of roll force redistribution 


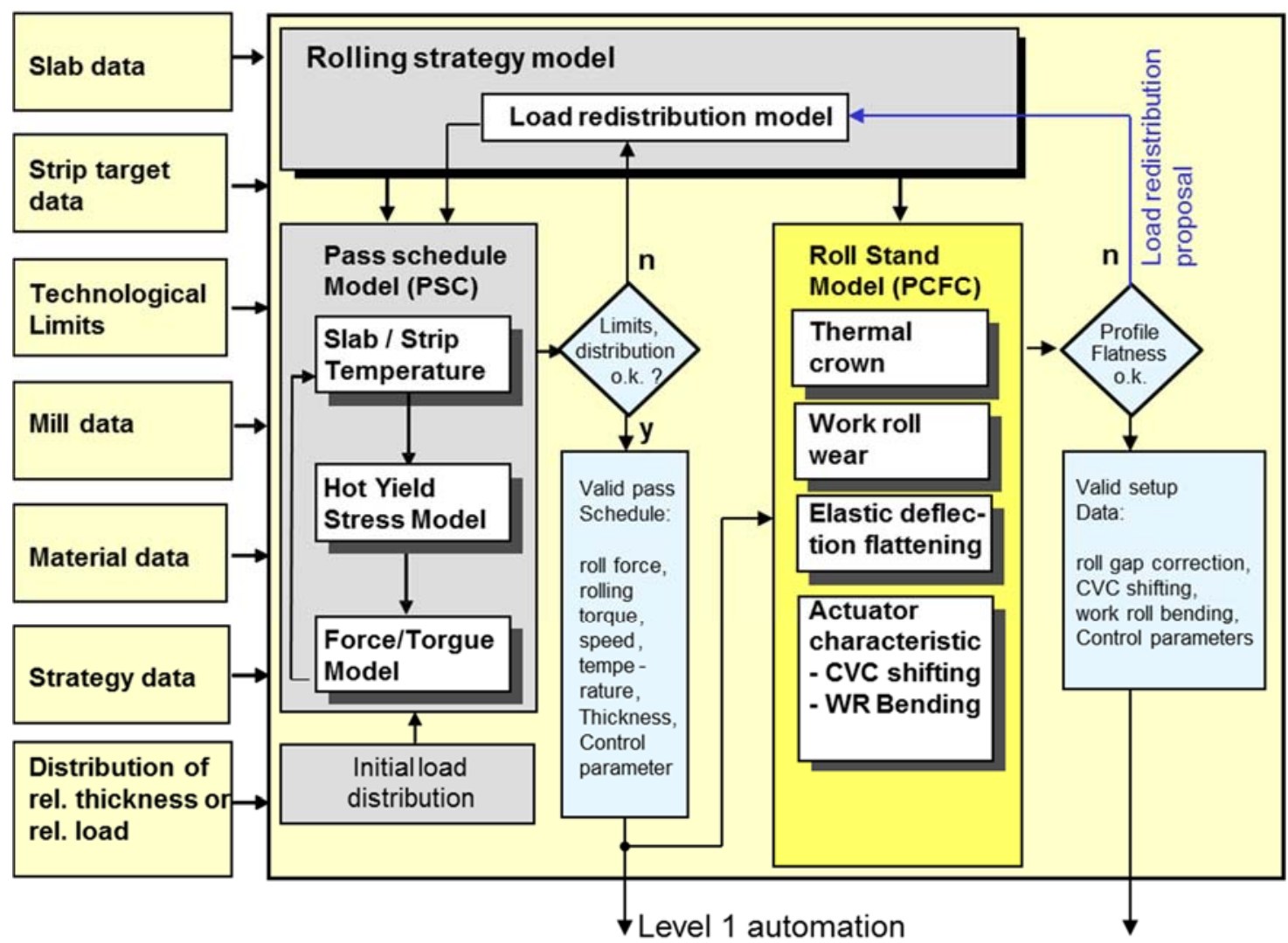

Figure 5: Interaction of $\mathrm{PSC}^{\circledR}$ and $\mathrm{PCFC}^{\circledR}$

\subsection{Cooling Section Control (CSC)}

Apart from the design, the efficiency of the cooling section process models is of major importance. After an analysis of the efficiency of existing models and meetings with several mill owners, SMS decided in the early nineties to develop a completely new model for meeting the ever-increasing demands of the market and the customers.

Since then various developments of the process model and of the automation concept have been done to increase the model accuracy and to improve the coiling temperature performance. E. g. while in the early CSC version the physical relations were used mainly for setup and adaption calculation purposes now the complete physical model is continuously used for in-bar temperature controlling over the entire strip length. Furthermore an enhanced calculation of the start and end temperatures of the phase transformation as well as the fractions of austenite, ferrite, bainite, pearlite and martensite has been integrated. As a result CCT diagrams for every material and every individual strip are calculated and made available for later verification purpose. These calculations are based on regression formulas that consider the chemical composition of the material and which are also a function of the temperature gradient in the cooling line. The knowledge of the CCT diagrams is an indispensable requirement to describe best the phase transformation and to reach the best possible temperature tolerances. 


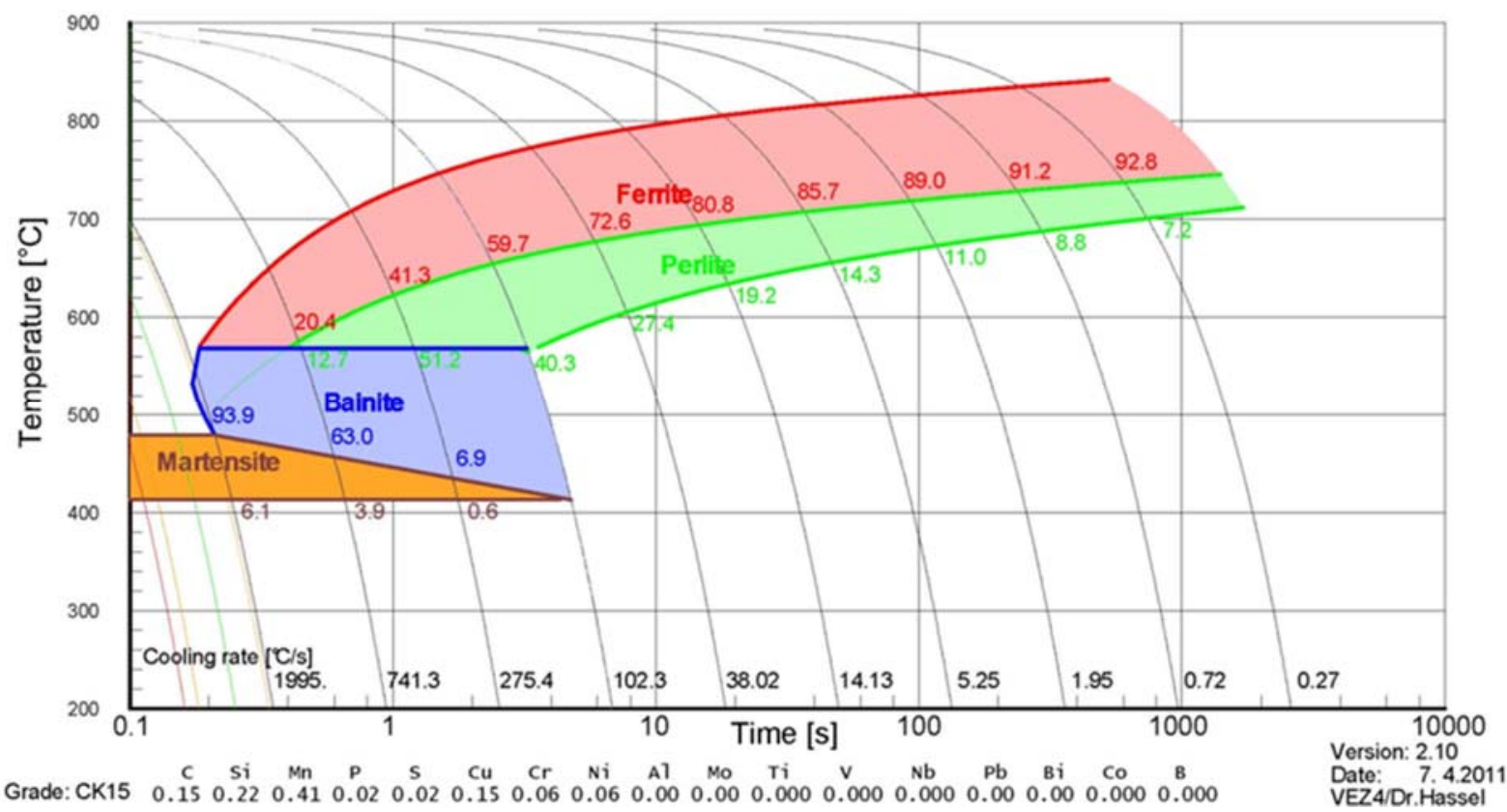

Figure 6: Example of a CCT diagram

\subsection{Material Property and Microstructure Model (MPM)}

The Material Property Model calculates the final strip properties (e.g. yield strength, tensile strength and elongation to fracture) as well as the material microstructure (e.g. material grain size, portion of ferrite, pearlite, bainite) for products in a hot strip mill. It considers the conditions and rolling behaviour for products in the different production stages of a hot rolling mill.

The prediction of the mechanical properties offers the following advantages:

- $\quad$ Reduced number of material samples save time and laboratory costs

- $\quad$ Prediction of material properties ensures a quicker quality release of strips after rolling

- Investigations of influence of certain chemical components (within definite ranges) to mechanical properties are possible (optimization of steel composition of specified grades, offline mode).

- Investigations of influence of certain process parameters to mechanical properties possible (optimization of process, offline mode)

- $\quad$ The optimization of steel composition and process parameters lead to a reduced number of rolling tests.

Figure 7 shows the general sequence of calculation steps to determine the material property values (e.g. yield and tensile strength).

These strength values are calculated:

- Using the strip input data and the initial microstructure of the material.

- Considering changes in the microstructure due to the deformation and transformation process of rolling.

- Considering the microstructure transformation due to the thermal changes in the cooling line. 


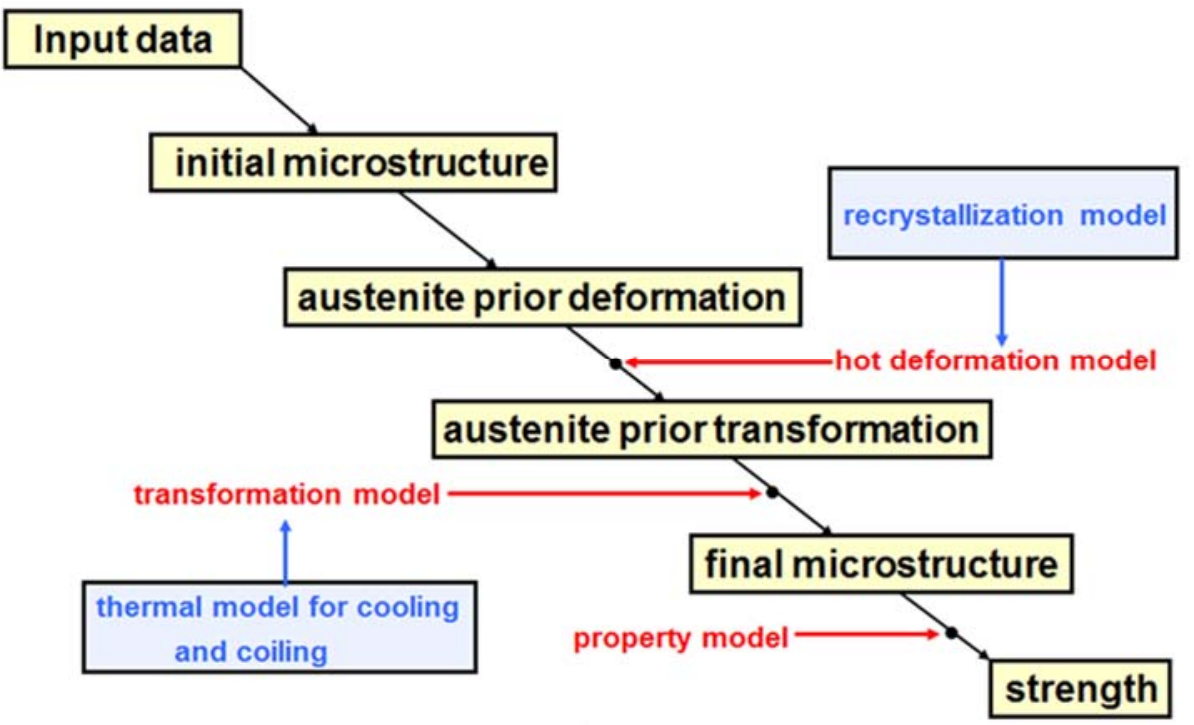

Figure 7: Sequence of calculation

During cooling a decomposition of the austenite phase, which is present after rolling, into the phases ferrite, pearlite, bainite and martensite occurs via nucleation of ferrite grains at the existing austenite grain boundaries. Depending on the cooling rate, the fractions of the various phases can change very much. For example to achieve the decomposition of austenite to martensite the actual cooling rate has to be higher than a critical cooling rate and for low cooling rates no martensite formation is possible. Taking into account the chemistry of the actual strip, the condition of the austenite grains and the influence of the cooling pattern/strategy the transformation temperatures for the formation of the new phases are calculated.

The kinetics of the phase transformation in consequence impacts the fractions of phases (austenite, ferrite, pearlite, bainite, martensite) present at the end of transformation and also the amount of each phase present at each point of the cooling line. Depending on the cooling rate the final ferrite grain size is calculated.

The final mechanical properties (ultimate tensile strength, yield strength, elongation) are finally calculated on the basis of the previously obtained results.

The microstructure model is available as online or offline model. In the online version it is an integral part of the PSC ${ }^{\circledR}$ and the CSC. The offline version is supplied together with a graphical user interface and allows either to simulate already rolled strips by using the logging facilities of the online system or to key in data manually. 

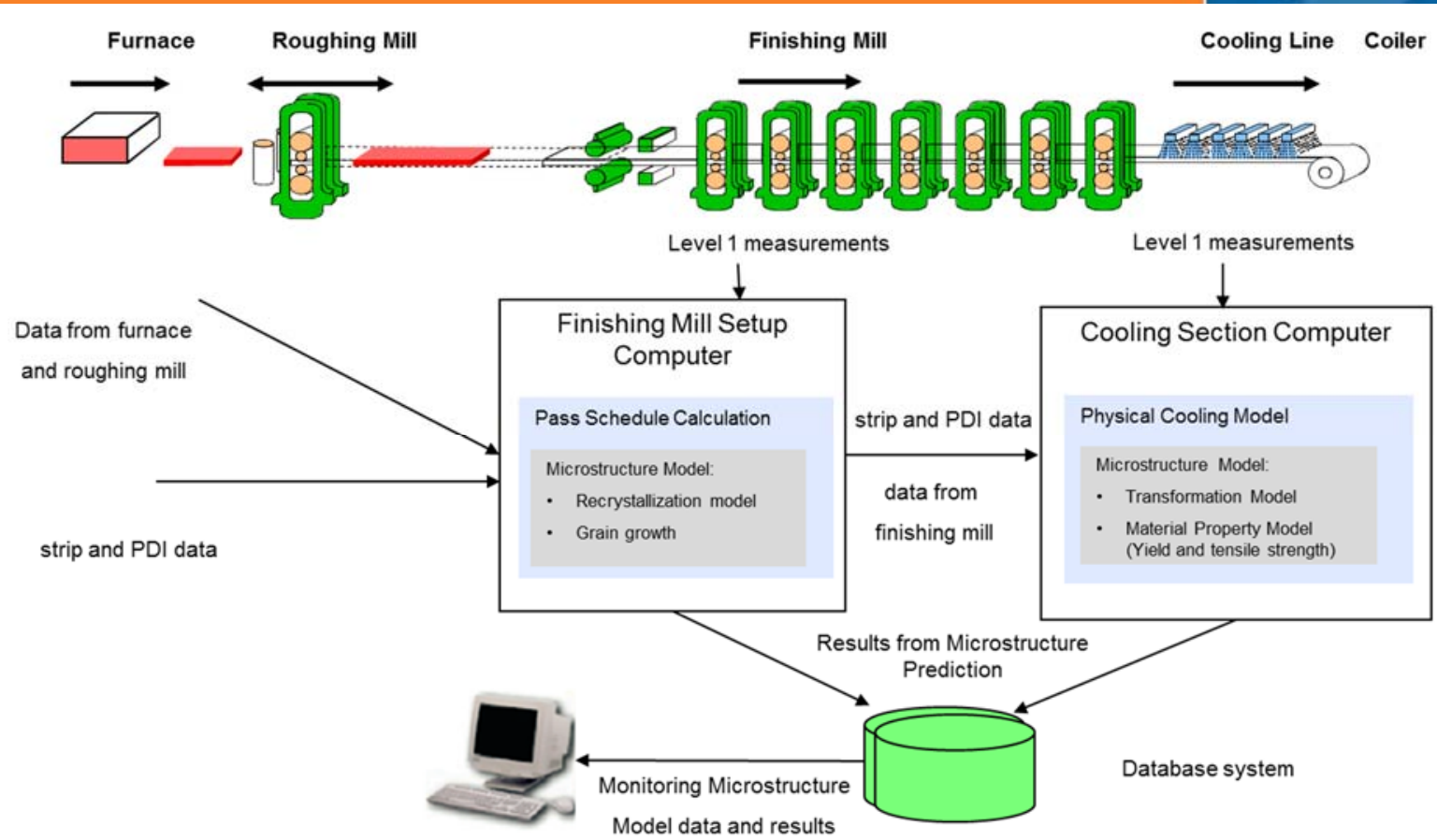

Figure 8: MPM system overview

Figure 9 shows a comparison between measured and calculated yield strength and tensile strength values. This evaluation bases on material samples taken from strips produced in a conventional hot strip mill.

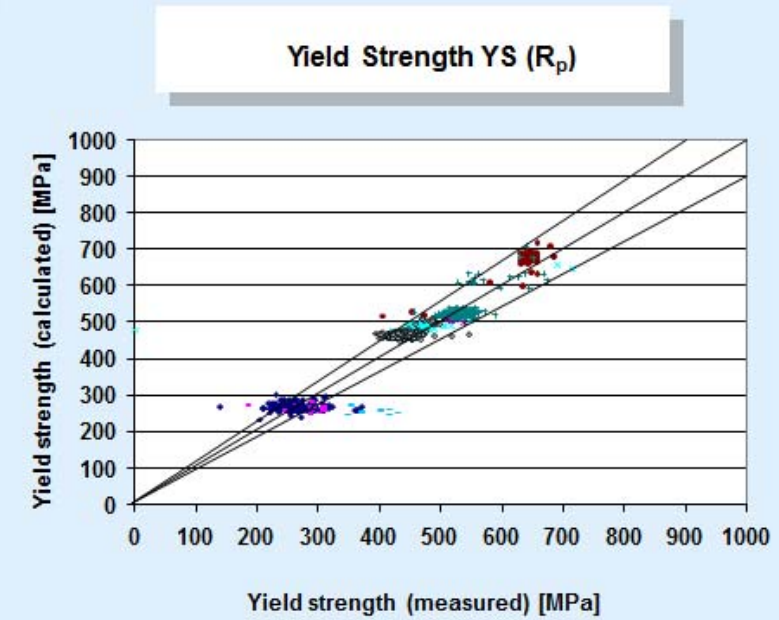

The specimens (measured values) have been taken At the last $8 \mathrm{~m}$ of the strip (end)

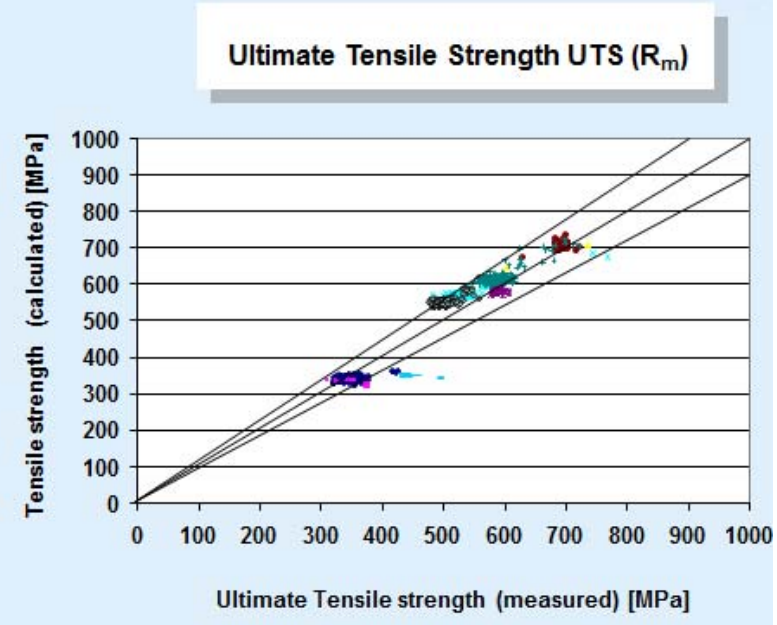

Rp 1.1 (LC) Rp 1.2 (LC) Rp 30.2 (MA) *Rp 31.2 (MA) -Rp 32.2 (MA) $+\operatorname{Rp} 34.2$ (MA) -Rp 40.1 (LC-Ti) -Rp 42.1(LC-Nb) ORp 42.2 (MA) - Rp 44.2 (MA)

Figure 9: Comparing measured strength values against calculated strength values 


\section{OUTLOOK}

In the near future it is also planned to use the intermediate results of the microstructure model for an integrated setup calculation of the laminar cooling model. Then the desired final material properties are predefined by customer via PDI and strip data. Basing on these given properties the MPM is choosing by itself the best matching cooling rate and cooling strategy to adjust the desired property values. This cooling strategy is then automatically considered and applied by the Level 2 CSC system.

The Microstructure and Material Property Model is also in scope of SMS Level 2 systems for plate mills.

\section{BIBLIOGRAPHY}

1 Iron \& Steel Technology Conference (AISTech), 2013, Pittsburg USA.

2 Automation and Information Technology in Iron \& Steel Making (AITISM), 2014, Ranchi, India.

3 Journées Sidérurgiques Internationales (JSI conference), 2014, Paris, France. 